\title{
16
}

\section{Simple Hydrograph Shapes for Urban Stormwater Water Quality Continuous Analyses}

\author{
Robert Pitt, John Voorhees and Caroline Burgess
}

Over the years, a number of different approaches have been used to represent hydrographs in urban areas for drainage design. Unit hydrographs are usually used to represent one inch of runoff and are scaled according to calculated total runoff amounts, and the hydrograph shapes are based on different drainage area characteristics. An actual complex rain distribution is then used to assemble a set of scaled unit hydrographs to represent the total storm event. As an example, the United States Department of Agriculture (USDA) developed different urban area hydrograph shapes which are dependent on expected rainfall distribution patterns. The simplest hydrograph shape is a triangle, while more complex hydrographs have more detailed recession curves and other features.

The need for accurate hydrograph representations for drainage design calculations has long been recognized for both single event design storm and for continuous simulations using long term rainfall records. The events of most interest in drainage design are obviously large and occur infrequently. Actual rainfall and flow records of these events are therefore rare, with little opportunity for verification of flow modeling tools.

Reasonable assumptions based on regional observations of selected large events that have occurred over long periods have therefore been the basis for most drainage design calculations. However, these assumptions and tools may not accurately represent the runoff conditions that occur during more frequent rains of most interest for use in water quality evaluations in urban areas (see Burton and Pitt, 2002; Pitt, 2002 for extensive summaries of the literature). Because these smaller rains are more common, it is likely that significant

Pitt, R.E., J. Voorhees and C. Burgess. 2012. "Simple Hydrograph Shapes for Urban Stormwater Water Quality Continuous Analyses." Journal of Water Management Modeling R245-16. doi: 
monitoring records exist that are suitable for calibration and subsequent verification of stormwater models.

This chapter reviews about 550 urban area hydrographs that have been collected at eight locations in four regions of North America, representing different land uses under widely varying rain conditions. Statistical analyses were performed to quantify the important shape factors of the observed hydrographs, applicable for water quality analyses that focus on small and intermediate-sized rains.

\subsection{Observed Urban Area Hydrographs}

Monitored hydrograph information has been routinely collected during stormwater monitoring projects for many years. This chapter reviews about 550 events that have been monitored at four North American locations since the late 1970s and were readily available for these analyses. These data include:

1. San Jose, California (Pitt, 1979). Residential and downtown commercial areas monitored as part of a United States Environmental Protection Agency (USEPA) funded project to measure the benefits of street and catchbasin cleaning. Figures 16.1 and 16.2 are examples of a complex and a simple hydrograph recorded during this research project;

2. Bellevue, Washington (Pitt, 1985). Residential and commercial areas monitored as part of the USEPA's Nationwide Urban Runoff project (NURP) (USEPA, 1983). Detailed flow information obtained through a joint monitoring effort with the United States Geological Survey;

3. Toronto, Ontario (Pitt and McLean, 1986). Residential, commercial and industrial areas monitored as part of the Toronto area wastewater management strategy study funded by the Ontario Ministry of the Environment; and

4. Tuscaloosa, Alabama (Khambhammettu et al., 2007; Pitt and Khambhammettu, 2006; Togawa et al., 2010). Small commercial areas mostly represented by directly connected parking and roof areas. These areas were monitored as part of USEPA and industry funded projects to test critical source area treatment devices. Figure 16.3 below is an observed large event hydrograph from the City Hall station. 


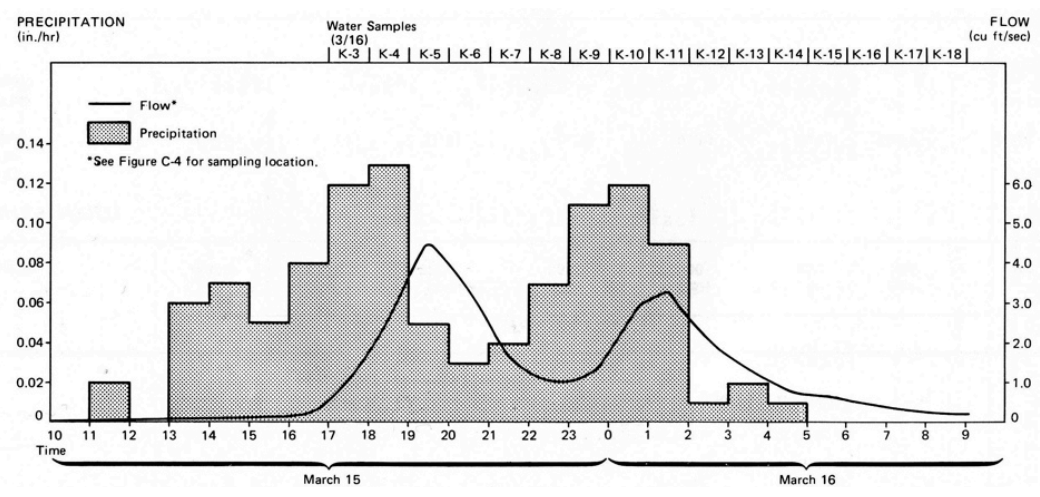

Figure 16.1 Keyes study area, San Jose, California 19770315 and 19770316 (1.06 in., 27 mm) (Pitt, 1979).

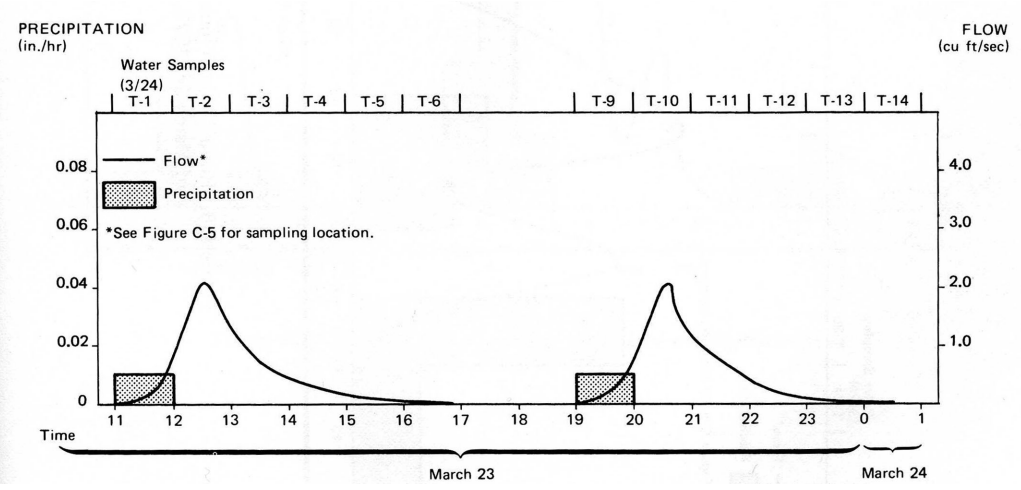

Figure 16.2 Tropicana study area, San Jose, California 19770323 (0.0 in., $0.25 \mathrm{~mm}$, and 0.01 in., $0.25 \mathrm{~mm}$ ) (Pitt, 1979).

The San Jose hydrographs are for relatively small rains and typical residential areas, with the rain intensities plotted in hourly increments, while the Tuscaloosa hydrographs are for larger rains for a small completely paved area, with the rain intensities plotted in 5 min increments. The San Jose rains were typical relatively low intensity and the areas are relatively large with low fractions of directly connected impervious areas, resulting in hydrographs that are smooth and of traditional shape. In contrast, the Tuscaloosa rains (Figure 16.3) included intense summer thunderstorms and one very large hurricane, and because the drainage area was small and paved, the hydrographs are much more complex. Table 16.1 is a summary of the characteristics of the monitored areas, the rains, and the runoff. 


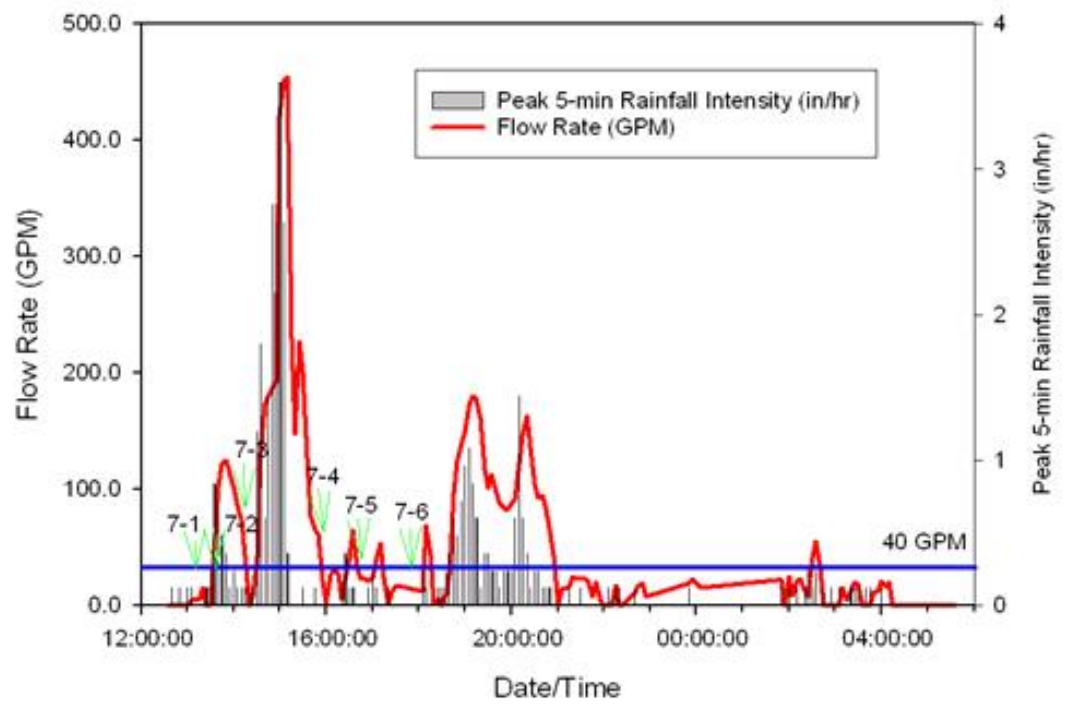

Figure 16.3 Tuscaloosa, Alabama City Hall, 20050829 (Hurricane Katrina, 3.2 in., $81 \mathrm{~mm}$ ) (Pitt and Khambhammettu, 2006).

Table 16.1a Monitored area characteristics.

\begin{tabular}{|c|c|c|c|c|c|c|}
\hline Location & Land use & $\begin{array}{c}\text { area } \\
\text { (acres) }\end{array}$ & $\begin{array}{c}\text { directly } \\
\text { connected } \\
\text { impervious } \\
(\%)\end{array}$ & $\begin{array}{c}\text { partially } \\
\text { connected } \\
\text { impervious } \\
(\%)\end{array}$ & $\begin{array}{l}\text { pervious } \\
(\%)\end{array}$ & $\begin{array}{l}\text { \# of events } \\
\text { monitored }\end{array}$ \\
\hline \multicolumn{7}{|l|}{ Bellevue, WA } \\
\hline Surrey Downs & $\begin{array}{l}\text { residential } \\
\text { medium density }\end{array}$ & 95.1 & 17 & 19 & 64 & 196 \\
\hline Lake Hills & $\begin{array}{l}\text { residential } \\
\text { medium density }\end{array}$ & 101.7 & 17 & 19 & 64 & 201 \\
\hline \multicolumn{7}{|l|}{ San Jose, CA } \\
\hline Keyes & $\begin{array}{l}\text { residential, } \\
\text { medium density }\end{array}$ & 92 & 30 & 22 & 48 & 6 (drought) \\
\hline Tropicana & $\begin{array}{l}\text { residential, } \\
\text { medium density }\end{array}$ & 195 & 25 & 19 & 56 & 8 (drought) \\
\hline \multicolumn{7}{|c|}{ Toronto, Ontario } \\
\hline $\begin{array}{l}\text { Thistledowns } \\
\text { (half swales) }\end{array}$ & $\begin{array}{l}\text { residential, } \\
\text { medium density }\end{array}$ & 96.4 & 21 & 24 & 55 & 35 \\
\hline $\begin{array}{l}\text { Emery } \\
\text { Tuscaloosa, A }\end{array}$ & industrial & 380.5 & 42 & 33 & 25 & 60 \\
\hline City Hall & $\begin{array}{l}\text { institutional/ } \\
\text { commercial }\end{array}$ & 0.9 & 100 & 0 & 0 & 31 \\
\hline BamaBelle & commercial & 0.89 & 68 & 0 & 32 & $\begin{array}{c}17 \\
\text { (on-going) }\end{array}$ \\
\hline
\end{tabular}


Table 16.1b Monitored area characteristics.

\begin{tabular}{lccccc}
\hline \multicolumn{1}{c}{ Location } & $\begin{array}{c}\text { monitored rains (in., } \\
\text { avg and range) }\end{array}$ & $\begin{array}{c}\text { Observed Rv } \\
\text { (avg and } \\
\text { range) }\end{array}$ & $\begin{array}{c}\text { Observed CN } \\
\text { (avg and range) }\end{array}$ & $\begin{array}{c}\text { Observed C } \\
\text { (avg and } \\
\text { range) }\end{array}$ & $\begin{array}{c}\text { peak/avg } \\
\text { flow ratio } \\
\text { (avg and } \\
\text { range) }\end{array}$ \\
\hline Bellevue, WA & 0.35 & 0.18 & 95 & 0.17 & 4.4 \\
Surrey Downs & $(0.03-4.38)$ & $(0.01-0.60)$ & $(64-100)$ & $(0.02-0.40)$ & $(1-14)$ \\
Lake Hills & 0.35 & 0.21 & 95 & 0.25 & 5.4 \\
& $(0.02-3.69)$ & $(0.01-0.49)$ & $(73-100)$ & $(0.02-0.54)$ & $(1.1-19)$ \\
San Jose, CA & 0.25 & 0.10 & 96 & 0.10 & 3.2 \\
Keyes & $(0.01-1.06)$ & $(0.01-0.28)$ & $(88-100)$ & $(0.01-0.37)$ & $(2.4-3.7)$ \\
Tropicana & 0.22 & 0.59 & 99 & 0.67 & 3.8 \\
& $(0.01-1.08)$ & $(0.17-1.6)$ & $(95-100)$ & $(0.18-1.0)$ & $(2.7-4.9)$ \\
Toronto, Ontario & 0.33 & 0.17 & 95 & 0.04 & 4.0 \\
Thistledowns & $(0.03-1.01)$ & $(0.02-0.37)$ & $(84-99)$ & $(0.01-0.12)$ & $(1.4-12)$ \\
(half swales) & 0.27 & 0.23 & 96 & 0.1 & 3.1 \\
Emery & $(0.03-1.0)$ & $(0.05-0.58)$ & $(87-99)$ & $(0.02-0.50)$ & $(1.3-8.3)$ \\
& & & & & \\
Tuscaloosa, AL & 0.7 & 0.6 & 98 & 0.3 & 4.2 \\
City Hall & $(0.02-3.2)$ & $(0.09-0.80)$ & $(95-99)$ & $(0.09-0.80)$ & $(1.1-8)$ \\
BamaBelle & 0.7 & 0.8 & 99 & 0.6 & 5.5 \\
& $(0.1-1.9)$ & $(0.3-1.0)$ & $(94-100)$ & $(0.3-0.9)$ & $(1.8-9.4)$ \\
\hline
\end{tabular}

$R v$ is the ratio of the monitored runoff quantity (represented as the depth of runoff over the complete area) to the rainfall depth. The observed $C N$ is the calculated curve number using the NRCS (National Resources Conservation Service, formerly the Soil Conservation Service, SCS) equations that define the $C N$ values as a function of the runoff depth $(Q)$ and the rain depth $(P)$, both expressed in inches:

$$
C N=1000 /\left[10+5 P+10 Q-10\left(Q^{2}+1.25 Q P\right)^{0.5}\right]
$$

The observed $C$ is the rational coefficient $\mathrm{C}$ factor, or the ratio of the instantaneous peak discharge $\left(Q, \mathrm{ft}^{3} / \mathrm{s}\right)$ to the peak rain intensity $(I, \mathrm{in} . / \mathrm{h})$.

Most of the flow observations used in this analysis are from the Bellevue NURP project, representing mostly residential areas, with some mixed commercial areas. The Toronto Emery site is the only industrial area shown here, while the Tuscaloosa sites are small mostly paved areas. The rains observed ranged from 0.01 in. $(0.25 \mathrm{~mm})$, which was sufficient to produce runoff at the San Jose study areas, to an extended rain that was about $4.5 \mathrm{in} .(110 \mathrm{~mm})$ in depth during the Bellevue monitoring. The recent Tuscaloosa locations are much smaller than the other sites, being about 1 acre $(0.4 \mathrm{ha})$, in contrast to the 100 acre to 200 acre ( 40 ha to $80 \mathrm{ha}$ ) areas of the other sites. Thus the range of rainfall conditions observed during these projects represented a wide range of expected conditions that are likely to be found throughout North America. 


\subsection{Modeling Hydrographs in Urban Areas}

Hydrological models predict flow distributions using a variety of methods. This section is not intended to be a review of these methods, for which extensive literature exists.

One method utilizes unit hydrographs which represent the flow distribution associated with $1 \mathrm{in}$. (25.4 $\mathrm{mm}$ ) runoff from a specific drainage area. These can be used to produce a complete storm hydrograph by scaling and separating the rain intensity into short time increments, as illustrated in Figure 16.4, while Figure 16.5 (below) defines the dimensions of the individual unit hydrographs.

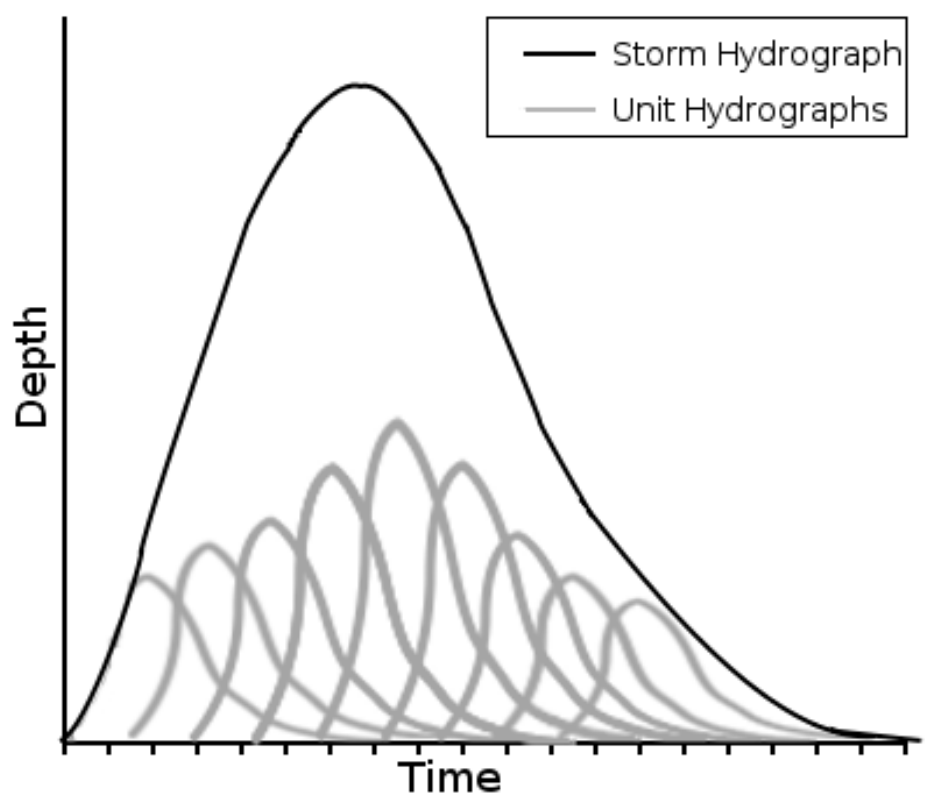

Figure 16.4 Superposition of unit hydrographs to form a storm hydrograph (UDFCD, 2010).

The individual unit hydrographs are developed using a variety of methods, including analyzing actual rainfall-runoff records, or by predicting the shape based on watershed characteristics. As an example, HEC-HMS (Feldman 2000) includes a number of unit hydrograph options available to the model user, including the SCS (NRCS) dimensionless unit graph, Clark unit hydrograph, Snyder unit hydrograph, user-defined, and ModClark unit hydrograph. These options each have unique attributes that the model user must evaluate for the best application for their site. 


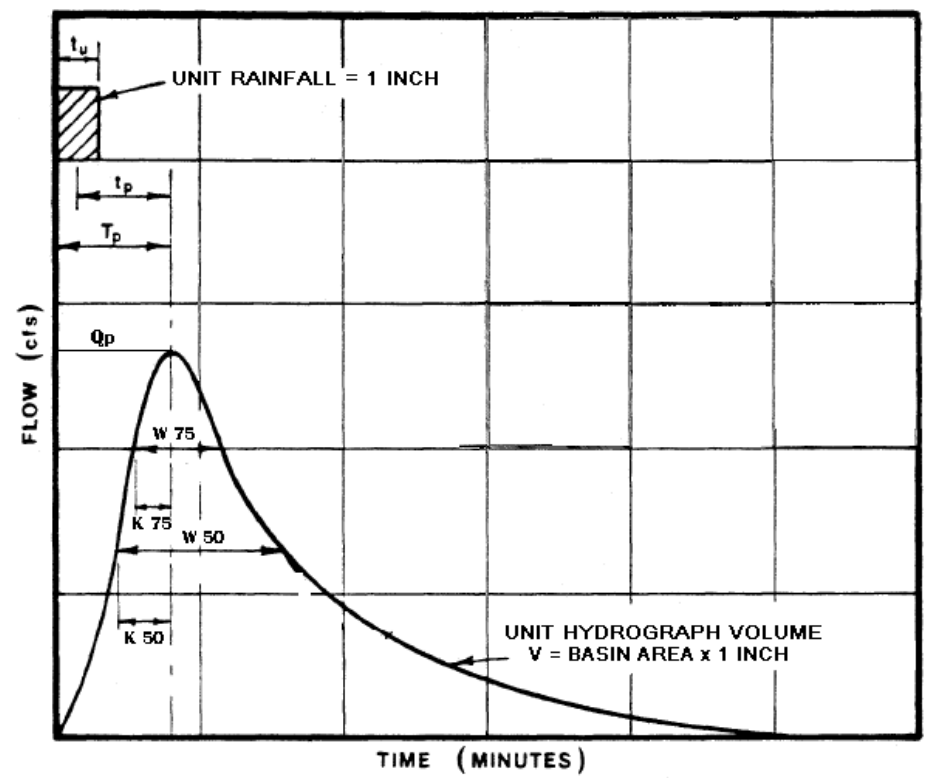

Figure 16.5 Colorado unit hydrograph parameters (UDFCD, 2010).

The NRCS (SCS) dimensionless hydrograph and triangular hydrograph is shown in Figure 16.6, showing how closely the smoothed hydrograph is represented by a simple triangle.

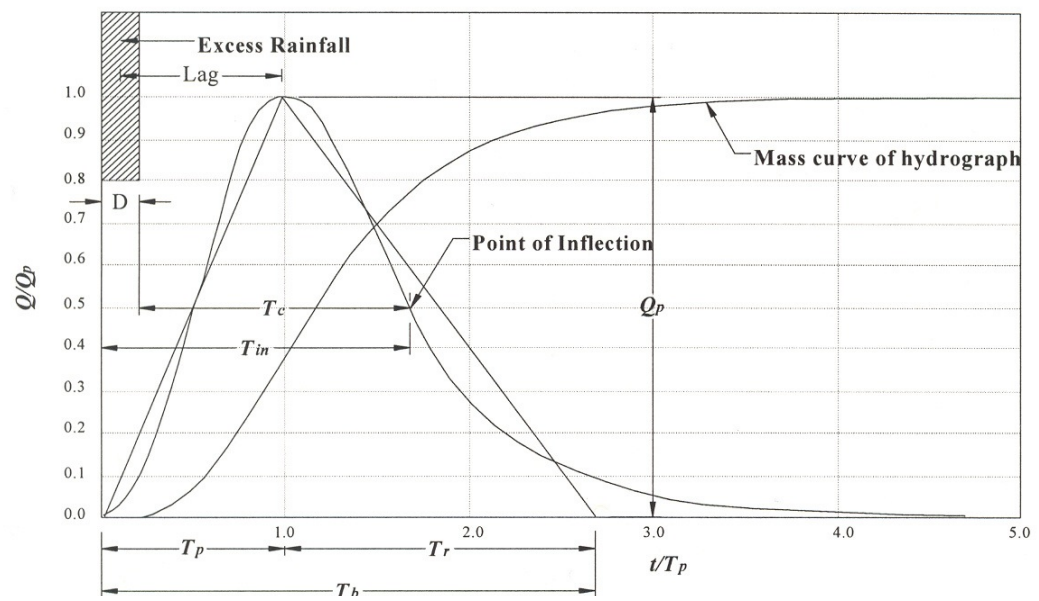

Figure 16.6 NRCS dimensionless unit hydrograph and triangular hydrograph. 
NRCS, in TR-55 (SCS 1986), developed storm hydrographs for different hypothetical rainfall distributions that were composite intensity and duration joint data sets representing severe storm conditions commonly used for drainage designs ( $2 \mathrm{y}$ to $100 \mathrm{y}$ storms). These hydrographs were not intended for representing smaller storms of most interest in water quality analyses, but were developed as an efficient tool for drainage design with relatively large rains.

\subsubsection{Calculated Unit Hydrographs Using WinTR-55}

WinTR-55 was used to calculate storm hydrographs for the eight watersheds. Table 16.2 summarizes the basic watershed characteristics from the site information and TR-55 (SCS, 1986).

Table 16.2 Basis watershed characteristics and TR-55 parameters.

\begin{tabular}{|c|c|c|c|c|c|c|}
\hline Location & Land use & $\begin{array}{c}\text { Area } \\
\text { (acres) }\end{array}$ & $\begin{array}{c}\text { Time of } \\
\text { Concentration, } \\
\text { Tc (min) }\end{array}$ & $\begin{array}{c}\text { NRCS rainfall } \\
\text { distribution } \\
\text { category }\end{array}$ & $\begin{array}{c}\text { Hydrologic } \\
\text { Soil Group } \\
\text { (HSG) }\end{array}$ & $\begin{array}{c}\text { CN (from } \\
\text { TR55) }\end{array}$ \\
\hline \multicolumn{7}{|l|}{ Bellevue, WA } \\
\hline Surrey Downs & Residential & 95 & 28.5 & $1 \mathrm{a}$ & $\mathrm{C}$ & 81 \\
\hline Lake Hills & Residential & 102 & 30.5 & $1 \mathrm{a}$ & $\mathrm{C}$ & 81 \\
\hline \multicolumn{7}{|l|}{ San Jose, CA } \\
\hline Keyes & Residential & 92 & 30 & 1 & $\mathrm{D}$ & 87 \\
\hline Tropicana & Residential & 195 & 40 & 1 & $\mathrm{D}$ & 87 \\
\hline \multicolumn{7}{|c|}{ Toronto, Ontario } \\
\hline Thistledowns & Residential & 96 & 19 & 2 & B & 75 \\
\hline Emery & Industrial & 381 & 32 & 2 & B & 88 \\
\hline \multicolumn{7}{|c|}{ Tuscaloosa, AL } \\
\hline City Hall & Commercial & 0.9 & 6 & 3 & $\mathrm{D}$ & 98 \\
\hline BamaBelle & Commercial & 0.9 & 6 & 3 & $\mathrm{D}$ & 92 \\
\hline
\end{tabular}

The time of concentration values were calculated using the TR-55 methods and ranged from $6 \mathrm{~min}$ for the small paved areas in Tuscaloosa, to $40 \mathrm{~min}$ for the large residential area in San Jose. The NRCS rain categories for these four locations represented all four possible rain distribution options, from mild types 1 and 1a on the west coast, to more intense type 3 in the southeast. The soil groups were based on the soil textures observed in the field. The curve number values were selected from the TR-55 tables based on the land use, soil type, and impervious percentages.

Table 16.3 summarizes the curve numbers observed at the watersheds during the monitoring. The $C N$ values were calculated based on the rainfall and runoff quantities and then compared as a function of rain depth (this is acknowledged as a spurious self-correlation, but was only used as an expedient method to sort the observed values for different rain ranges). As expected, based on data from many locations previously evaluated, the $C N$ values are all 
very large for the smallest rains and then decrease as the rain depth increases. In most cases, the $C N$ values approach the TR-55 table CN values shown in Table 16.2 for rains greater than $1.5 \mathrm{in}$. $(38 \mathrm{~mm})$. For smaller rains, the actual runoff amounts are greater than expected if using a constant $C N$ value for all rains.

Table 16.3 Curve numbers based on monitored rainfall and runoff.

\begin{tabular}{lccccc}
\hline \multicolumn{1}{c}{ Location } & $\begin{array}{c}\text { CN for } \\
0.25 \text { in. rains }\end{array}$ & $\begin{array}{c}\text { CN for } \\
0.50 \text { in. rains }\end{array}$ & $\begin{array}{c}\text { CN for } \\
1.0 \text { in. rains }\end{array}$ & $\begin{array}{c}\text { CN for } \\
1.5 \text { in. rains }\end{array}$ & $\begin{array}{c}\text { CN for } \\
2.5 \text { in. rains }\end{array}$ \\
\hline Bellevue, WA & & & & & \\
$\begin{array}{l}\text { Surrey Downs } \\
\text { Lake Hills }\end{array}$ & 96 & 93 & 87 & 81 & 72 \\
$\begin{array}{l}\text { San Jose, CA } \\
\begin{array}{l}\text { Keyes } \\
\text { Tropicana }\end{array}\end{array}$ & 96 & 94 & 90 & 86 & 79 \\
$\begin{array}{l}\text { Toronto, Ontario } \\
\text { Thistledowns }\end{array}$ & 93 & 92 & 90 & 89 & 88 \\
$\begin{array}{l}\text { Emery } \\
\text { Tuscaloosa, AL }\end{array}$ & 96 & 97 & 97 & 96 & 96 \\
$\begin{array}{l}\text { City Hall } \\
\text { BamaBelle }\end{array}$ & 96 & 92 & 86 & 81 & 74 \\
\hline
\end{tabular}

Table 16.4 summarizes the results of the WinTR-55 evaluations of these eight watersheds, using the $C N$ values as obtained from the Tables in TR-55, while Table 16.5 summarize the same hydrograph characteristics using the observed $C N$ values.

Table 16.4 Hydrograph characteristics for 1 in. $(25 \mathrm{~mm})$ rains using Table 16.3 CN values from TR-55.

\begin{tabular}{|c|c|c|c|c|c|c|}
\hline Location & $\begin{array}{l}\text { peak } \\
\text { flow } \\
\left(\mathrm{ft}^{3} / \mathrm{s}\right)\end{array}$ & $\begin{array}{l}\text { avg } \\
\text { flow } \\
\left(\mathrm{ft}^{3} / \mathrm{s}\right)\end{array}$ & $\begin{array}{c}\text { peak/avg } \\
\text { flow rate } \\
\text { ratio }\end{array}$ & $\begin{array}{c}\text { rain } \\
\text { duration }(h)\end{array}$ & $\begin{array}{c}\text { runoff } \\
\text { duration } \\
\text { (h) }\end{array}$ & $\begin{array}{c}\text { runoff/rain } \\
\text { duration } \\
\text { ratio }\end{array}$ \\
\hline \multicolumn{7}{|l|}{ Bellevue, WA } \\
\hline Surrey Downs & 0.71 & 0.6 & 1.2 & 24 & 16 & 0.67 \\
\hline Lake Hills & 0.76 & 0.63 & 1.2 & 24 & 16 & 0.67 \\
\hline \multicolumn{7}{|l|}{ San Jose, CA } \\
\hline Keyes & 6 & 1.32 & 4.6 & 24 & 15 & 0.63 \\
\hline Tropicana & 4.1 & 2.64 & 1.6 & 24 & 16 & 0.67 \\
\hline \multicolumn{7}{|c|}{ Toronto, Ontario } \\
\hline Thistledowns & 0.36 & 0.23 & 1.6 & 24 & 13 & 0.54 \\
\hline Location & 71 & 7.5 & 9.5 & 24 & 14 & 0.58 \\
\hline \multicolumn{7}{|l|}{ Bellevue, WA } \\
\hline Surrey Downs & 0.69 & 0.12 & 5.8 & 24 & 2.5 & 0.1 \\
\hline Lake Hills & 0.37 & 0.12 & 3.1 & 24 & 1.5 & 0.06 \\
\hline
\end{tabular}


Table 16.5 Hydrograph characteristics for 1 in. $(25 \mathrm{~mm})$ using observed $C N$ values during monitoring.

\begin{tabular}{lcccccc}
\hline \multicolumn{1}{c}{ Location } & $\begin{array}{c}\text { peak } \\
\text { flow } \\
\left(\mathrm{ft}^{3} / \mathrm{s}\right)\end{array}$ & $\begin{array}{c}\text { avg } \\
\text { flow } \\
\left(\mathrm{ft}^{3} / \mathrm{s}\right)\end{array}$ & $\begin{array}{c}\text { peak/avg flow } \\
\text { rate ratio }\end{array}$ & $\begin{array}{c}\text { rain } \\
\text { dura- } \\
\text { tion }(\mathrm{h})\end{array}$ & $\begin{array}{c}\text { runoff } \\
\text { duration } \\
(\mathrm{h})\end{array}$ & $\begin{array}{c}\text { runoff/rain } \\
\text { duration } \\
\text { ratio }\end{array}$ \\
\hline $\begin{array}{l}\text { Bellevue, WA } \\
\text { Surrey Downs }\end{array}$ & 2.2 & 1.26 & 1.7 & 24 & 17 & 0.71 \\
$\begin{array}{l}\text { Lake Hills } \\
\text { San Jose, CA }\end{array}$ & 5.0 & 1.95 & 2.5 & 24 & 18 & 0.75 \\
$\begin{array}{l}\text { Keyes } \\
\text { Tropicana }\end{array}$ & 11 & 1.93 & 5.8 & 24 & 16 & 0.67 \\
$\begin{array}{l}\text { Toronto, Ontario } \\
\text { Thistledowns }\end{array}$ & 56 & 6.73 & 8.3 & 24 & 22 & 0.92 \\
$\begin{array}{l}\text { Emery } \\
\text { Tuscaloosa, AL }\end{array}$ & 18 & 1.83 & 9.7 & 24 & 14 & 0.58 \\
$\begin{array}{l}\text { City Hall } \\
\text { BamaBelle }\end{array}$ & 0.64 & 7.5 & 9.5 & 24 & 14 & 0.58 \\
\hline
\end{tabular}

As noted above, the TR-55 $C N$ values are lower than expected, even for the 1 in. $(25 \mathrm{~mm})$ rain, except for one location. Figures 16.7 and 16.8 are plots of the actual hydrographs for the Bellevue and Tuscaloosa locations and indicate the dramatic differences in the hydrograph shapes when using the two different $C N$ values for the same sites.

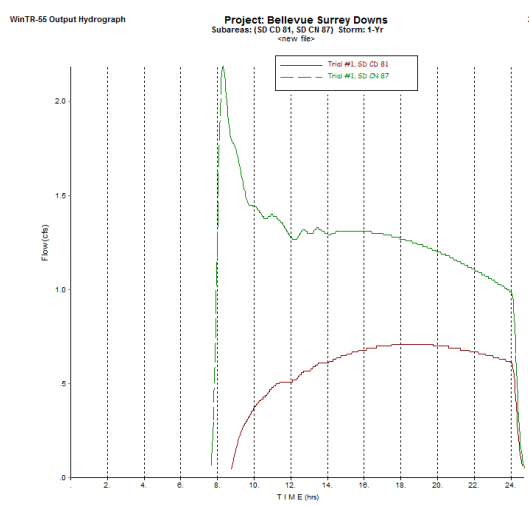

Bellevue, WA, Surrey Downs, medium density residential area, 1 inch rain, TR55CN 81 and observed 87

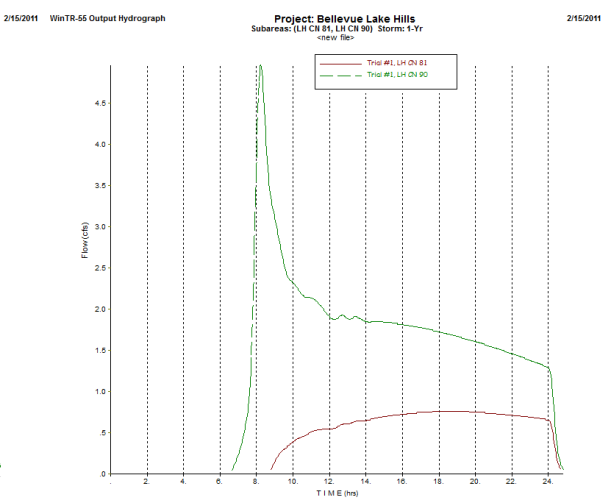

Bellevue, WA, Lake Hills, medium density residential area, 1 inch rain, TR55CN 81 and observed 90

Figure 16.7 WinTR-55 hydrographs for Bellevue, Washington sites (type 1a rain distributions). 


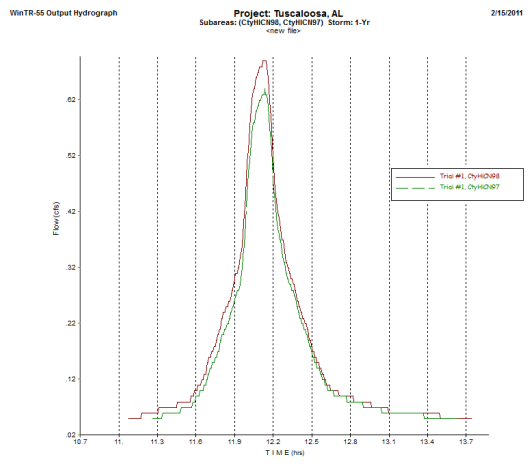

Tuscaloosa, AL, City Hall, institution$\mathrm{al} /$ commercial area, 1 in. rain, TR55CN 98 and observed 97

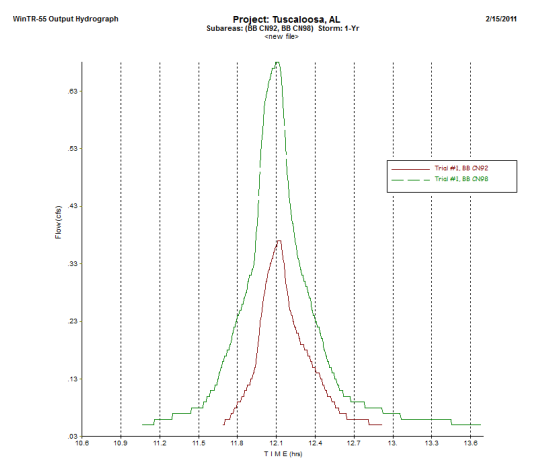

Tuscaloosa, AL, BamaBelle, landscaped parking area, 1 in. rain, TR55CN 92 and observed 98

Figure 16.8 WinTR-55 hydrographs for Tuscaloosa, Alabama sites (type 3 rain distributions).

The hydrograph features summarized in these two tables include the instantaneous peak flow rate and the average flow rate over the event (in $\mathrm{ft}^{3} / \mathrm{s}$ ), and their ratio, along with the rain duration and runoff duration (both in $\mathrm{h}$ ) and the duration ratios. The rain duration values are assumed to be $24 \mathrm{~h}$ based on the TR-55 rainfall distribution characteristics, although most of the rainfall occurs near the middle of the duration.

The distortion of the rainfall distribution is greater for the type 2 and type 3 distributions than for the type 1 and type $1 \mathrm{a}$. The ratios of the flows and durations are smaller when using the smaller $C N$ values that when using the larger observed $C N$ values. The shapes of the hydrographs for the type 1a rainfall distributions are greatly distorted, with the peak flows occurring near the beginning of the event for the higher $C N$ condition; for the smaller $C N$ conditions, the flows are more evenly distributed. In both cases, the flows abruptly end. This is likely associated with the low flows calculated for these conditions.

\subsection{Hydrograph Characteristics Used in WinSLAMM}

All of the hydraulic routing that is done in WinSLAMM and WinDETPOND is based upon a complex triangular storm hydrograph (see Pitt, 1997; 1999; Pitt and Voorhees, 2002 for descriptions of WinSLAMM). This hydrograph shape was selected to reflect a typical urban hydrograph, and is flexible to represent a range of conditions. The total discharge quantity is calculated for the drainage area while the shape of the hydrograph is a function of the runoff to rainfall 
duration ratio and the peak flow to average flow ratio. The runoff duration is assumed to be 1.2 times the rainfall duration. The average flow is calculated by dividing the runoff volume WinSLAMM calculates for each event by the runoff duration. This average value is multiplied by the peak to average flow ratio to obtain the peak flow for the event. The model then creates the hydrograph, as shown below, based upon the peak flow, the runoff duration and the inflection points in the hydrograph. This shape provides the flow rates for each time step used to calculate the performance of wet detention ponds, catchbasins and hydrodynamic devices, biofilters, porous pavement and grass swales.

WinSLAMM version 10 will also use this hydrograph shape for new controls added to the model, including grass filters and green roofs. It will also have the ability to route flows (starting with this basic hydrograph shape), and particle size distributions, through series of stormwater controls located at many source area, drainage system and outfall locations. Figure 16.9 is an example of a hydrograph that has a typical peak to average flow ratio of 3.8 , a rainfall duration of $1 \mathrm{~h}$ and a runoff volume of $0.25 \mathrm{in}(6.4 \mathrm{~mm})$ over a 1 acre $(0.4 \mathrm{ha})$ land surface.

\section{Complex Triangular Hydrograph}

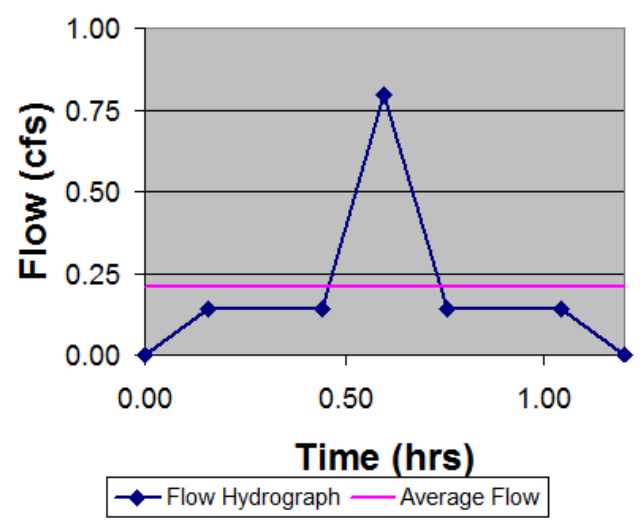

Figure 16.9 Example of the complex triangular hydrograph used in WinSLAMM for routing flows through stormwater control practices.

\subsection{Analyses of Observed Urban Hydrograph Shapes}

In order to determine the most reasonable hydrograph shape parameters (peak to average flow ratios and runoff to rain duration ratios) for the WinSLAMM 
complex triangular hydrograph, statistical analyses were conducted on the approximate 550 observed urban area hydrographs described above. The rainfall and flow data from the hydrographs were entered into Excel spreadsheets from archived project records and the published reports. The data were then separated by land use and sorted by rain depth, and copied into SigmaPlot (version 11 from SYSTAT.com) for statistical analyses and plotting.

\subsubsection{Peak to Average Flow Ratios}

A 2-way ANOVA was initially examined to identify the effects and interactions of the main factors of land use and rain depth on the peak to average flow rate ratios of the approximately 550 hydrographs. Unfortunately, the interactions could not be calculated due to lack of data for some conditions, so a general linear model was used. The data also failed the normality (Shapiro-Wilk) test and the equal variance tests, making any parametric ANOVA analysis improper. Therefore, the following analyses focused on the non-parametric KruskalWallis 1-way ANOVA test that is based on ranks, examining the land use and rain characteristics separately.

Figure 16.10 is a box and whisker plot illustrating the medians, along with the 25 th and 75 th percentiles in the grey boxes and the 5 th and 95 th percentiles at the end of the whiskers, of the peak to average flow ratios for different rain depth categories. Observations less than or greater than these values are shown as dots. These rain range categories were selected to result in a reasonably large number of observations in each group (41 to 191).

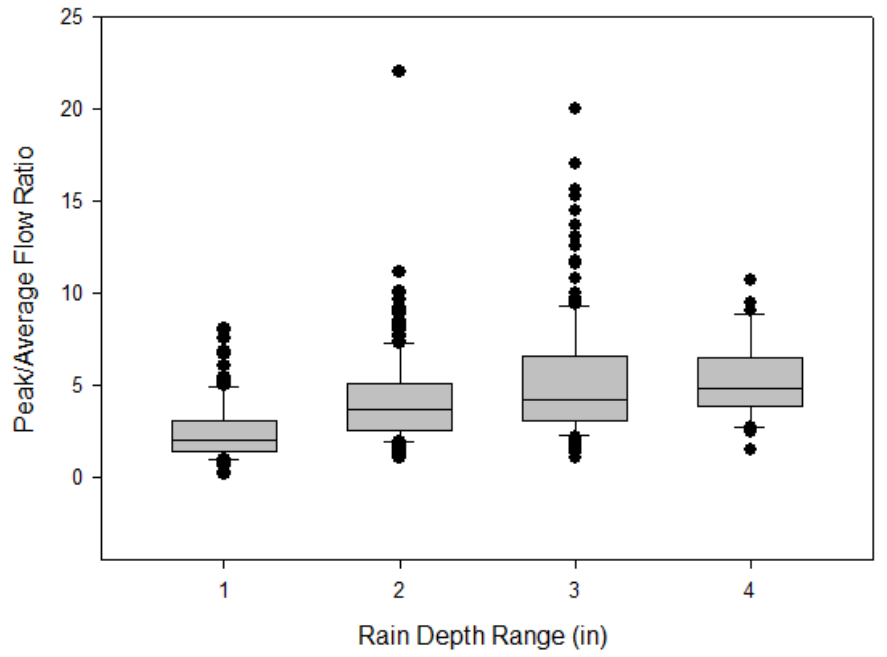

Figure 16.10 Peak to average runoff ratios for all sites combined, separated into four rain depth categories. 
The ranges used in Figure 16.10 are:

- $\quad$ rain range 1: $0.01 \mathrm{in}$. to $0.09 \mathrm{in}$. $(0.25 \mathrm{~mm}$ to $2.3 \mathrm{~mm})$;

- $\quad$ rain range $2: 0.1$ in. to 0.29 in. $(2.5 \mathrm{~mm}$ to $7.4 \mathrm{~mm})$;

- rain range $3: 0.3 \mathrm{in}$. to $0.99 \mathrm{in}$. (7.6 $\mathrm{mm}$ to $25 \mathrm{~mm})$; and

- rain range 4: 1.0 in. to $4.4 \mathrm{in.} \mathrm{(25} \mathrm{to} 110 \mathrm{~mm}$ ).

Table 16.6 is the non-parametric Kruskal-Wallis 1-way ANOVA (based on ranks), indicating that there is at least one significant difference between the rain groups.

Table 16.6 Non-parametric Kruskal-Wallis 1-way ANOVA.

\begin{tabular}{lccccc}
\hline \multicolumn{1}{c}{ Group } & $\mathrm{N}$ & Missing & Median & $25 \%$ & $75 \%$ \\
\hline very small & 130 & 0 & 2.012 & 1.412 & 3.071 \\
small & 191 & 0 & 3.640 & 2.520 & 5.029 \\
medium & 188 & 0 & 4.148 & 3.026 & 6.561 \\
large & 41 & 0 & 4.768 & 3.800 & 6.467 \\
\hline
\end{tabular}

$\mathrm{H}=121.309$ with 3 degrees of freedom. $(\mathrm{P}=<0.001)$

Dunn's method was then used to conduct a pairwise multiple comparison to isolate the group, or groups, that differ from the others. The results are shown in Table 16.7.

Table 16.7 Dunn's method.

\begin{tabular}{lcccc}
\hline \multicolumn{1}{c}{ Comparison } & Diff of Ranks & $\mathrm{Q}$ & $\mathrm{P}<0.05$ & \\
\hline large vs very small & 222.38 & & 7.813 & Yes \\
large vs small & 89.422 & 3.269 & Yes & \\
large vs medium & 39.435 & 1.440 & No & \\
medium vs very & 182.95 & 10.093 & Yes & \\
small & & & & Yes \\
medium vs small & & 49.987 & 3.062 & \\
small vs very small & 132.96 & 7.359 & Yes & \\
\hline
\end{tabular}

Therefore, the large and medium rain groups were combined to result in only three rain categories, as shown in Figure 16.11 below. The Kruskal-Wallis and Dunn's tests indicated that these groupings were significant $(\mathrm{p}<0.001)$.

The next step was to examine the effects of land use on the peak to average flow rate ratios, as shown in Figure 16.12. The statistical tests indicated that the commercial and residential area data should be combined, while the industrial area peak to flow rate values were significantly less than for this combined category. Figure 16.13 shows the plot of these two main land use categories. The Mann-Whitney U statistical test indicated that the medians values between the two resulting groups are much greater than would be expected by chance $(\mathrm{p}<0.001)$. 


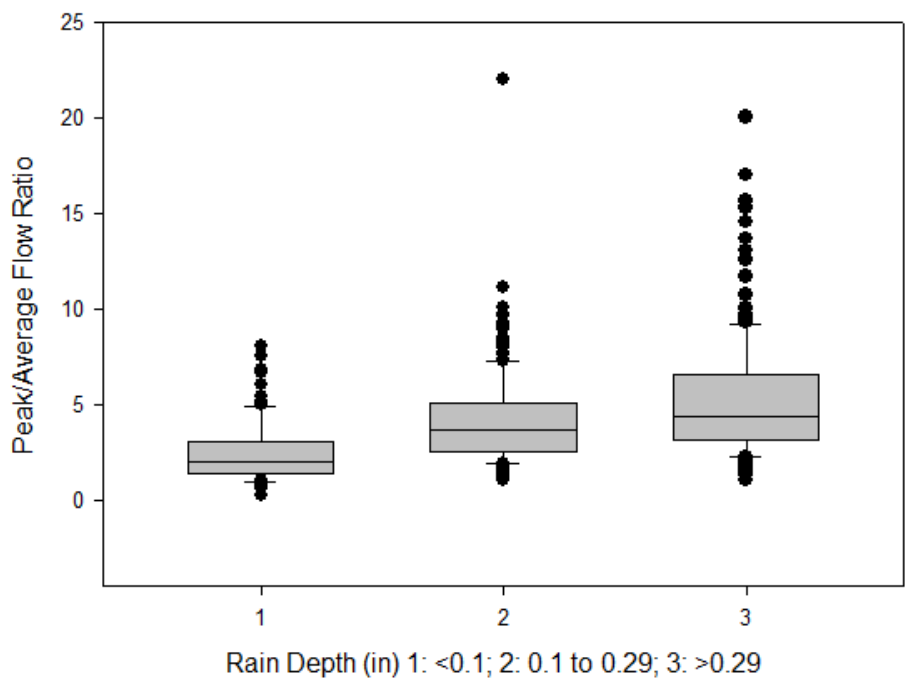

Figure 16.11 Three rain groups representing the range of observed peak to average flow ratios.

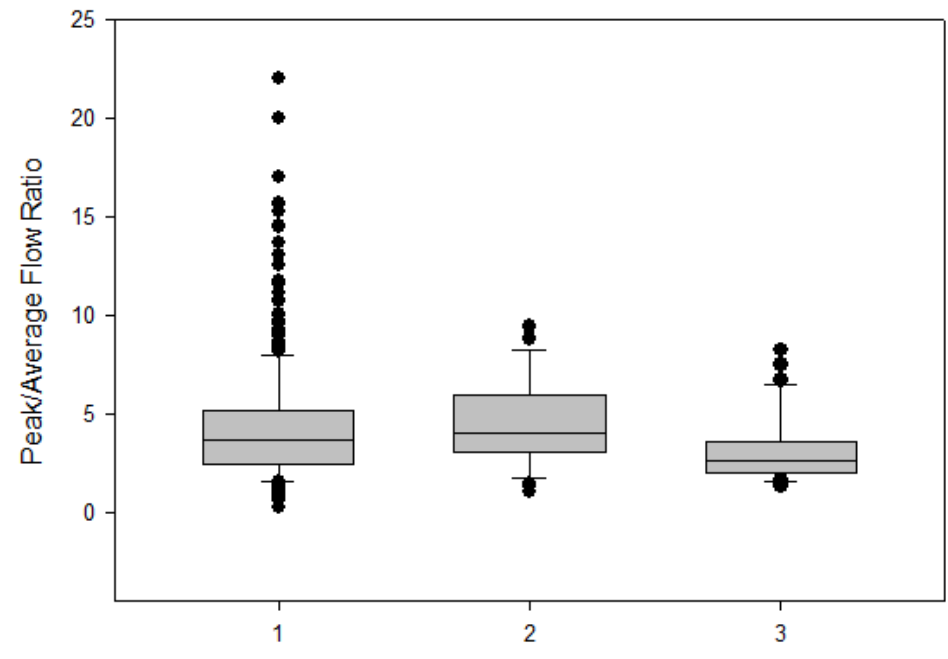

Land Use (1: residential; 2: commercial; 3: industrial)

Figure 16.12 Land use effects on the observed peak to average flow rate ratios. 


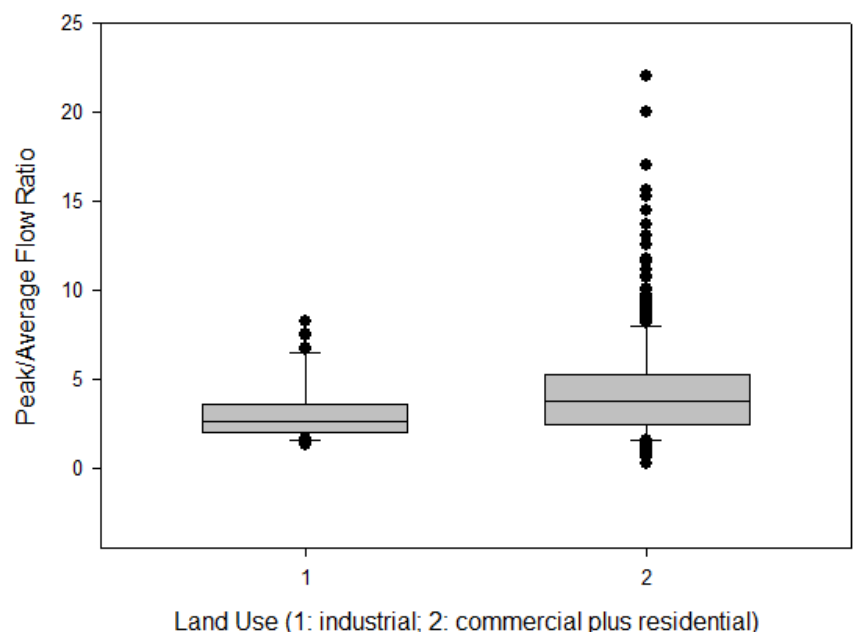

Figure 16.13 Combined land use effects on the peak to average flow ratios.

The next step was to examine these two land use group individually to indicate it they should be separated according to rain groupings. The industrial group did not have sufficient data to indicate that grouping was necessary, based on the Kruskal-Wallis tests $(\mathrm{p}=0.054)$. The industrial data were therefore combined into one group, irrespective of rain depth. When the combined residential plus commercial data were examined by rain groups, the KruskalWallis and Dunn's tests indicated that they should remain separated in the three rain groupings.

The last tests examined these four groups (one industrial and three commercial plus residential) to determine of further data groupings were appropriate. These tests indicated that the industrial data should be combined with the very small rain category of the commercial plus residential observations, as indicated in Tables 16.8 and 16.9.

Table 16.8 Kruskal-Wallis 1-way analysis of variance on ranks.

\begin{tabular}{lccccc}
\hline \multicolumn{1}{c}{ Group } & $\mathrm{N}$ & Missing & Median & $25 \%$ & $75 \%$ \\
\hline $\mathrm{C}+\mathrm{R}$ very small +I & 172 & 0 & 2.283 & 1.597 & 3.189 \\
$\mathrm{C}+$ R small & 172 & 0 & 3.792 & 2.539 & 5.110 \\
$\mathrm{C}+\mathrm{R}$ medium + large & 206 & 0 & 4.652 & 3.373 & 6.710 \\
\hline
\end{tabular}

$\mathrm{H}=131.502$ with 2 degrees of freedom. $(\mathrm{P}=<0.001)$ 
Table 16.9 All pairwise multiple comparison procedures (Dunn's method).

\begin{tabular}{lrrr}
\hline \multicolumn{1}{c}{ Comparison } & Diff of Ranks & Q & P $<0.05$ \\
\hline C + R medium vs C + R very small & 186.882 & 11.386 & Yes \\
C + R medium vs C + R small & 65.051 & 3.963 & Yes \\
C + R small vs C + R very small & 121.831 & 7.110 & Yes \\
\hline
\end{tabular}

The differences in the median values among the treatment groups are greater than would be expected by chance; there is a statistically significant difference $(\mathrm{P}=<0.001)$ as shown in Table 16.9.

Figure 16.14 presents the final three categories of land use and rain categories representing significantly different peak to average flow ratios.

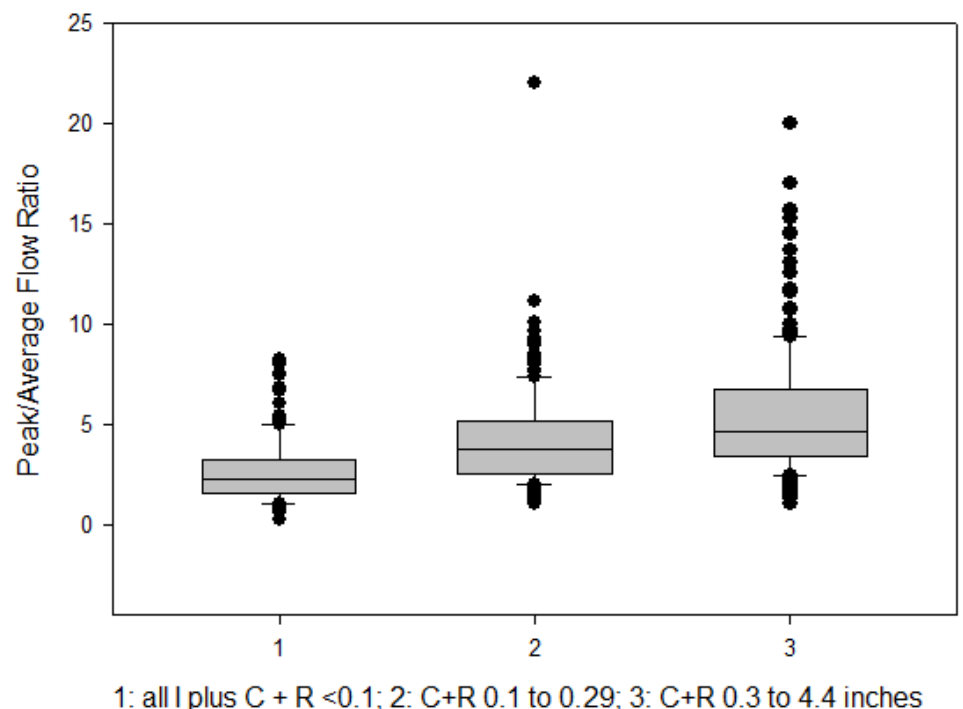

Figure 16.14 Final three categories of land uses and rain groupings for peak to average flow ratios for urban areas.

Because of the small number of industrial site observations (and they only represent a single location), these data should probably be combined for all of the basic land uses, with the different categories representing the rain ranges only.

\subsubsection{Runoff to Rain Duration Ratios}

A 2-way ANOVA was also initially used for these analyses to examine the effects and interactions of the main factors of land use and rain depth on the 
runoff to rain duration ratios. Unfortunately, the normality and equal variance test failed with these data also. As there are no equivalent nonparametric 2-way ANOVA tests, these initial results are only used to help structure more robust analyses. These initial results indicated that the land use and rain category interactions were likely significant, and that the rain categories should be combined into two groups, the very small group $(<0.1 \mathrm{in} ., 2.5 \mathrm{~mm})$ and the other rains, resulting in four possible categories: very small rains in industrial areas; other rains in industrial areas; very small rains in commercial and residential areas, and other rains in commercial and residential areas.

A 1-way ANOVA was then used to examine these four categories. Because the normality test also failed for these groups, the Kurskal-Wallis 1-way ANOVA on ranks test was used on the four groups shown in Table X.10.

Table 16.10 Kurskal-Wallis 1-way ANOVA on ranks test.

\begin{tabular}{lccccc}
\hline \multicolumn{1}{c}{ Group } & $\mathrm{N}$ & Missing & Median & $25 \%$ & $75 \%$ \\
\hline industrial very small & 20 & 0 & 3.008 & 2.208 & 4.920 \\
industrial larger & 40 & 1 & 1.202 & 1.047 & 1.633 \\
residential very small & 114 & 6 & 0.900 & 0.547 & 1.498 \\
residential larger & 333 & 2 & 0.905 & 0.719 & 1.143 \\
\hline
\end{tabular}

$\mathrm{H}=70.987$ with 3 degrees of freedom. $(\mathrm{P}=<0.001)$

The differences in the median values among the treatment groups are greater than would be expected by chance; there is a statistically significant difference $(\mathrm{p} \leq 0.001)$.

To isolate the group or groups that differ from the others, the all pairwise multiple comparison procedure (Dunn's Method) was used, as shown in Table 16.11 .

Table 16.11 Dunn's method.

\begin{tabular}{lccc}
\hline \multicolumn{1}{c}{ Comparison } & Diff of Ranks & $\mathrm{Q}$ & $\mathrm{P}<0.05$ \\
\hline industrial very sm vs residential very sm & 217.531 & 6.210 & Yes \\
industrial very sm vs residential larger & 215.741 & 6.511 & Yes \\
industrial very sm vs industrial larger & 80.196 & 2.026 & No \\
industrial larger vs residential very sm & 137.334 & 5.108 & Yes \\
industrial larger vs residential larger & 135.545 & 5.564 & Yes \\
residential larger vs residential very sm & 1.789 & 0.112 & No \\
\hline
\end{tabular}

Therefore, combine land uses: Residential/Commercial vs Industrial. The Mann-Whitney rank sum test was used to confirm that these two groups are significantly different, as shown in Table 16.12. 
Table 16.12 Mann-Whitney.

\begin{tabular}{lccccc}
\hline \multicolumn{1}{c}{ Group } & $\mathrm{N}$ & Missing & Median & $25 \%$ & $75 \%$ \\
\hline Residential & 447 & 8 & 0.905 & 0.693 & 1.167 \\
Industrial & 60 & 1 & 1.421 & 1.098 & 3.170 \\
\hline
\end{tabular}

Mann-Whitney U Statistic $=4464.000$

$\mathrm{T}=23207.000 \mathrm{n}($ small $)=59 \mathrm{n}(\mathrm{big})=439(\mathrm{P}=<0.001)$

The difference in the median values between the two groups is greater than would be expected by chance; there is a statistically significant difference $(\mathrm{p} \leq 0.001)$

Figure 16.15 illustrates the range and medians of the flow to rainfall duration ratios.

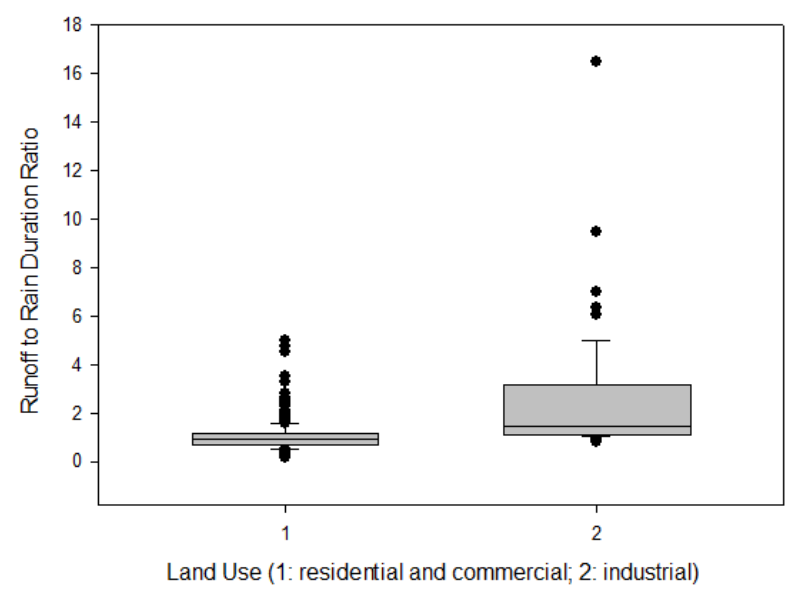

Figure 16.15 Final two categories representing runoff to rain duration ratios.

\subsection{Conclusions}

Table 16.13 summarizes the characteristics of the three land use and rain categories that were found to be significantly different in their peak to average flow ratios. This table also shows the characteristics of the combined data set. As expected, there is a slight, but significant, increase in the peak:average flow ratio as the rain depth increases. Analyses (not reported here) were also conducted to attempt to further explain the variability left in these groups. No significant patterns were observed for rain intensity or duration, antecedent dry period, season, or other factors. Therefore, it is suggested that these average ratio values be adjusted according to these significant categories when conduct- 
ing long term continuous simulations, and that Monte Carlo stochastic components of runoff models vary the average values according to the coefficient of variation values, for different rains in each category.

Table 16.13 Peak to average flow rate ratios for urban areas.

\begin{tabular}{lcccc}
\hline & $\begin{array}{c}\text { All Industrial } \\
\text { plus Commer- } \\
\text { cial and } \\
\text { Residential } \\
\text { areas for }<0.10 \\
\text { in. rains }\end{array}$ & $\begin{array}{c}\text { Commercial and } \\
\text { Residential } \\
\text { areas for 0.10 in. } \\
\text { to }\end{array}$ & $\begin{array}{c}\text { Commercial and } \\
\text { Residential areas } \\
\text { for 0.30 in. to } \\
4.4 \text { in. rains }\end{array}$ & $\begin{array}{c}\text { All data } \\
\text { combined (all } \\
\text { land uses and } \\
\text { all rain depths) }\end{array}$ \\
\hline Observations & 172 & 172 & 206 & 550 \\
Minimum & 1.00 & 1.00 & 1.05 & 1.00 \\
Maximum & 8.3 & 22 & 20 & 22 \\
Average & 2.67 & 4.22 & 5.42 & 4.18 \\
Median & 2.28 & 3.79 & 4.65 & 3.54 \\
Std. deviation & 1.57 & 2.45 & 3.06 & 2.72 \\
COV & 0.55 & 0.65 & 0.66 & 0.65 \\
\hline
\end{tabular}

Applying these shape factors to urban hydrographs when examining small and intermediate sized rains, which are of greatest interest to stormwater quality managers, will improve the sizing and designs of stormwater quality control practices. It is likely that similar data are available for many locations and that all stormwater quality models be compared to the locally available data during model calibration activities. As an example, the ratio values observed and presented here for these events are about half of the values that may be traditionally used for drainage design calculations when considering large events.

Table 16.14 summarizes the flow duration to rain duration ratios that are used to calculate the baseline duration for the urban hydrographs.

Table 16.14 Runoff duration to rain duration ratios for urban areas.

\begin{tabular}{lcccc}
\hline & \multicolumn{2}{c}{ Runoff Duration to Rain Duration Ratios } & \\
\cline { 2 - 4 } & $\begin{array}{c}\text { Residential and } \\
\text { Commercial Areas }\end{array}$ & $\begin{array}{c}\text { Industrial } \\
\text { Areas }\end{array}$ & $\begin{array}{c}\text { All data combined } \\
\text { (all land uses and } \\
\text { all rain depths) }\end{array}$ & $\begin{array}{c}\text { Rain depth } \\
\text { (in.) }\end{array}$ \\
\hline Observations & 447 & 60 & 507 & 507 \\
Minimum & 0.16 & 0.78 & 0.16 & 0.01 \\
Maximum & 5.0 & 16 & 16 & 4.34 \\
Average & 1.0 & 2.5 & 1.2 & 0.34 \\
Median & 0.91 & 1.4 & 0.97 & 0.20 \\
Std. deviation & 0.63 & 2.6 & 1.2 & 0.40 \\
COV & 0.63 & 1.0 & 1.0 & 1.2 \\
\hline
\end{tabular}

The statistical analyses indicated that the land use categories were significantly different in these ratios, with residential and commercial areas having flow durations about equal to the rain durations on the average; however, the 
variation is relatively large. The flow to rain duration ratios for the industrial areas are much larger, being about 2.5 on the average, and with even larger variations. The rain categories were examined in an attempt to explain some of this variability, but with minimal success. As for the peak to average flow rate ratios, it is recommended that a Monte Carlo routine be used in continuous modeling to randomly vary the duration ratios with the land use categories.

These analyses examined a set of about 550 different monitored rainfall and runoff events from four areas in North America, each paired with another site. These eight monitored areas represent each of the four rainfall distribution types, and represent typical ranges of drainage areas, land uses, and rain depths. Obviously, with the variations observed for these urban hydrographs, other locations may have hydrograph characteristics within a relatively wide range. However, as shown in the following histograms (Figures 16.16 and 16.17), most of the observations are within a relatively narrow range, and indicate lognormal distributions.
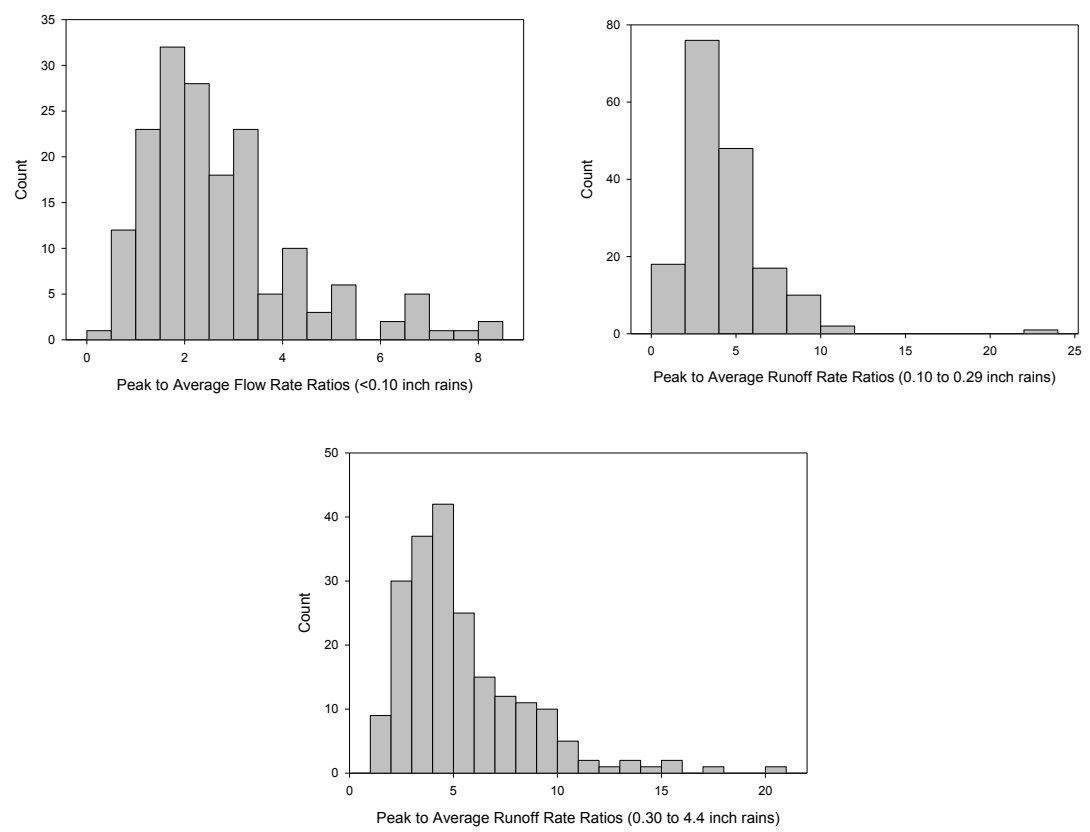

Figure 16.16 Histograms of observed peak to average runoff rate ratios. 

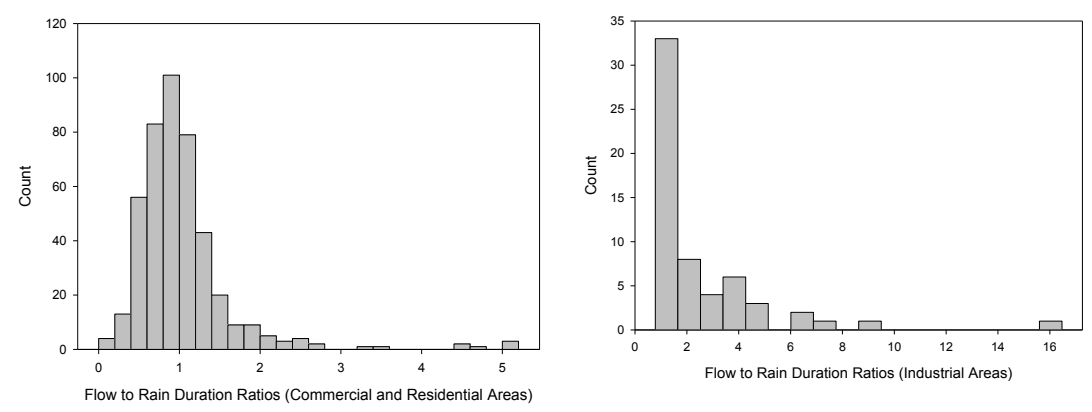

Figure 16.17 Histograms for observed runoff flow to rain duration ratios.

Uncalibrated, or partially calibrated (such as only for runoff quantity) runoff models likely greatly distort the actual hydrograph shapes that occur in urban areas. This dramatically affects the flow duration calculations needed for receiving water habitat evaluations. Simple models, such as WinTR-55, cannot be adequately and completed calibrated for an area for a wide range of rain conditions. It is possible to calculate the correct total runoff volume for an area over an extended period of time by adjusting the curve number value, but small rains would be under-reported and large rains would be over-reported to compensate for the non-constant actual curve numbers. It is not possible to calibrate TR-55 methods for peak flows, as the storm hydrographs are based on a composite highly distorted rainfall distribution that includes combined features of a number of large rains. The TR-55 methods were originally developed for single event analyses to examine relatively rare and large drainage design storms, a very worthwhile objective. However, the many simplifying assumptions used in its development preclude its accurate use for a wide range of continuous events of interest in either water quality or habitat stability analyses.

In contrast, complex hydrologic models can be appropriately calibrated to accurately represent a wide range of rain and watershed conditions. Both runoff volumes and flow distributions can be reasonably well matched with observed conditions. However, if uncalibrated and traditional model parameters are used without checking with observed data for similar conditions (an unfortunately common occurrence), distorted flow conditions are likely, especially for unfamiliarly modeled smaller events. As an example, typical peak to average flow ratios are likely greatly over-predicted when using uncalibrated models in urban areas.

WinSLAMM uses a hydrograph generation approach intermediate to these examples. The complex triangular storm hydrograph can be modified in shape for site conditions based on relatively simple data evaluations (the peak to flow 
rate ratios and the runoff to rain duration ratios). Currently, a single set of these ratios are used for all of the rains in an analysis, usually a ratio of 3.8 for the flow ratio value and 1.2 for the duration ratio value, which are shown to be close to the overall average observed. Future model changes are planned that will enable these ratios to vary based on both the site and storm factors identified in this chapter, and will include Monte Carlo type stochastic methods to account for the remaining uncertainty in the model calculations.

\section{References}

Burton, G.A. Jr., and R. Pitt. Stormwater Effects Handbook: A Tool Box for Watershed Managers, Scientists, and Engineers. ISBN 0-87371-924-7. CRC Press, Inc., Boca Raton, FL. 2002. 911 pages.

Feldman, A.D., editor. HEC HMS Technical Reference Manual, CPD-74B, Hydrologic Engineering Center, US Army Corps of Engineers, Davis, CA, March 2000.

Khambhammettu, U., R.E. Pitt, R. Andoh and S. Clark. 2007. "Upflow Filtration for the Treatment of Stormwater at Critical Source Areas." Journal of Water Management Modeling R227-09. doi: 10.14796/JWMM.R227-09.

Pitt, R. Demonstration of Nonpoint Pollution Abatement Through Improved Street Cleaning Practices, EPA-600/2-79-161, U.S. Environmental Protection Agency, Cincinnati, Ohio. 270 pgs. 1979.

Pitt, R. Characterizing and Controlling Urban Runoff through Street and Sewerage Cleaning. U.S. Environmental Protection Agency, Storm and Combined Sewer Program, Risk Reduction Engineering Laboratory. EPA/600/S2-85/038. PB 85-186500. Cincinnati, Ohio. 467 pgs. June 1985.

Pitt, R. and J. McLean. Humber River Pilot Watershed Project, Ontario Ministry of the Environment, Toronto, Canada. 483 pgs. June 1986.

Pitt, R.E. 1997. "Unique Features of the Source Loading and Management Model (SLAMM)." Journal of Water Management Modeling R200-02. doi: 10.14796/JWMM.R200-02.

Pitt, R.E. 1999. "Small Storm Hydrology and Why it is Important for the Design of Stormwater Control Practices." Journal of Water Management Modeling R204-04. doi: 10.14796/JWMM.R204-04.

Pitt, R. "Receiving water impacts associated with urban runoff." In: Handbook of Ecotoxicology, $2^{\text {nd }}$ edition (Edited by D.J. Hoffman, B.A. Rattner, G.A. Burton, Jr. and J.Cairns, Jr.). Lewis Publishers/CRC Press, Boca Raton. pp 79 - 101. 2002.

Pitt, R. and J. Voorhees. "SLAMM, the Source Loading and Management Model." In: Wet-Weather Flow in the Urban Watershed (Edited by Richard Field and Daniel Sullivan). CRC Press, Boca Raton. pp 103 - 139. 2002.

Pitt, R. and U. Khambhammettu. Field Verification Tests of the UpFlow Filter. Small Business Innovative Research, Phase 2 (SBIR2) Report. U.S. Environmental Protection Agency, Edison, NJ. 275 pages. March 2006. 
SCS (Soil Conservation Service), now NRCS. Urban Hydrology for Small Watersheds, TR-55. USDA, Natural Resources Conservation Service, Washington, DC. June 1986.

Togawa, N., R. Pitt, B. Andoh and K. Osei. "Stormwater treatment by upflow filtration device." WEFTEC, the 83rd Annual Water Environment Federation Technical Exhibition and Conference. New Orleans, LA, October 2-6, 2010. Conference CD.

UDFCD (Urban Drainage and Flood Control District). Colorado Urban Hydrograph Procedure. Denver, CO, 2010.

USEPA (U.S. Environmental Protection Agency). Results of the Nationwide Urban Runoff Program. Water Planning Division, PB 84-185552, Washington, D.C., December 1983. 